\title{
A Survey on House Sparrow Population Decline at Bandel, West Bengal, India
}

\author{
Samik Ghosh', Ki-Hyun Kim ${ }^{1, *}$, and R Bhattacharya ${ }^{2}$ \\ 'Department of Earth \& Environmental Sciences, Sejong University, Seoul 143-747, Korea \\ ${ }^{2}$ Department of Environmental Science, University of Kalyani, West Bengal, India
}

\begin{abstract}
The population of House sparrow (Passer domesticus), once a very common bird, has declined markedly in most parts of the world including India. Sparrows were distributed widely in the district Hoogly, West Bengal, India. However over the past few decades, they became not so common in this part of the world. A study has been conducted to establish the database for their current population and to assess the possible causes of their decline at Bandel $\left(22^{\circ} 52^{\prime} 22^{\prime \prime} \mathrm{N} / 88^{\circ} 22^{\prime} 53^{\prime \prime} \mathrm{E}\right)$ placed beside the river Hoogly from September 2008 to May 2009. After prolonged searching, a relatively dense population of sparrow (total subject 270) was found in busy areas of railway station and a nearby market in Bandel. The behavior of these birds was studied extensively from early morning to late night. The noise level of the area varied from 35 to $95 \mathrm{~dB}$ with an average of $70.6 \mathrm{~dB}$ from 04:30 am-10:30 pm. IST. It was also observed that the sparrows took rest on the site of the tree where the illumination level was low (30-45 lux). Sparrows residing at the Bandel station are habituated with the loud noise, being undisturbed by passing trains. Thus, it can be concluded that in spite of heavy noise of trains, crowdy travelers, and lack of nest sites, they remain at the station because of availability of food in the nearby roadside market. Based on this observation, sound pollution and availability of food are not responsible for their decline.
\end{abstract}

Keywords: House sparrow decline, sound pollution, bird pollution, prolonged search

\section{Introduction}

Birds are common inhabitants of our ecosystem. House sparrows are distributed widely in India and abroad. As they are generally associated with human habitation, they tend to stay in the region with structures built of many holes under the tiles. These sites may provide nestling sites and green areas for insect food. According to the latest sparrow census reported by various environmental organizations, there has been an 80 percent decline in their numbers during the past decades in India. The disappearance of sparrows in India has been widely reported, although responses have been quite muted. Their recent decline around the world has put them in the list of the International Union for the Conservation of Nature (IUCN). In an effort to draw the attention of government agencies and the scientific community for

\footnotetext{
*Corresponding author: khkim@sejong.ac.kr

Tel: 82-2-499-9151

Fax: 82-2-499-2354
}

more conservation measures and researches on common bird species and urban biodiversity, March 20 has been designated as World House Sparrow Day (www.worldhousesparrowday.org). The marking of the day is an international initiative by the Nature Forever Society, in collaboration with the Bombay Natural History Society, Cornell Lab of Ornithology (U.S.), Eco-Sys Action Foundation (France), Avon Wildlife Trust (U.K.) and numerous other international organizations. In recent years, India has seen a sharp decline of several bird species including Vulture, Great Indian Bustard, Sarus Crane, and sparrows. Over the past decade, India has lost more than 95 percent of its vulture population. A number of hypotheses have been put forward as possible causes of the decline of house sparrows in urban-suburban habitats: predation, competition, lack of nest sites, disease, food availability and pollution (Summers-Smith, 1999). An investigation has been conducted to know why the population of house sparrow, once a very common bird, declined so dramatically not only in India but around the world. Another objective of this 
investigation was also to see if surrounding environment has any impact on the maintenance of sparrow population.

\section{Materials and Methods}

After a prolong searching in the neighboring areas of Hoogly and Chinchura, a group of sparrows were spotted at Bandel $\left(22^{\circ} 52^{\prime} 22^{\prime \prime} \mathrm{N} / 88^{\circ} 22^{\prime} 58^{\prime \prime} \mathrm{E}\right)$ (Fig. 1). Bandel railway station (sampling site 1) and nearby market (sampling site 2) are identified as the residential area of house sparrows in that locality (Fig. 2). This is unexpected, as sparrows are known to reside in old houses. Normally they remain at the same place in the early morning. After that, they go out together to the nearby roadside market near the railway station in search of food. Hence, early morning is chosen as the ideal time for counting of house sparrows in the railway station. The same method was applied to count sparrows in the market place in the afternoon. Thus, their population was counted twice a day. On both the occasions, the number of sparrows was not many, while the counting was not seen to be constant. Hence, other counting methods like the line transect method or 'marking' method were not used.

The observations were carried out from October 2008 to May 2009. Because both locations are busy and noisy, the noise levels were also measured from 4:30 am to $10: 30 \mathrm{pm}$ (once in every thirty minutes). As the sparrows take nest in a tree of the railway station full of halogen lights, the illumination level was also measured using a digital lux meter in several places of the study areas twice per day. To collect the opinions regarding the decline of sparrow in that locality, a survey was also conducted among the local people with age group of 20-70 years.

\section{Results and Discussion}

\section{General aspects of sparrow population}

The size of sparrow populations is quantified at

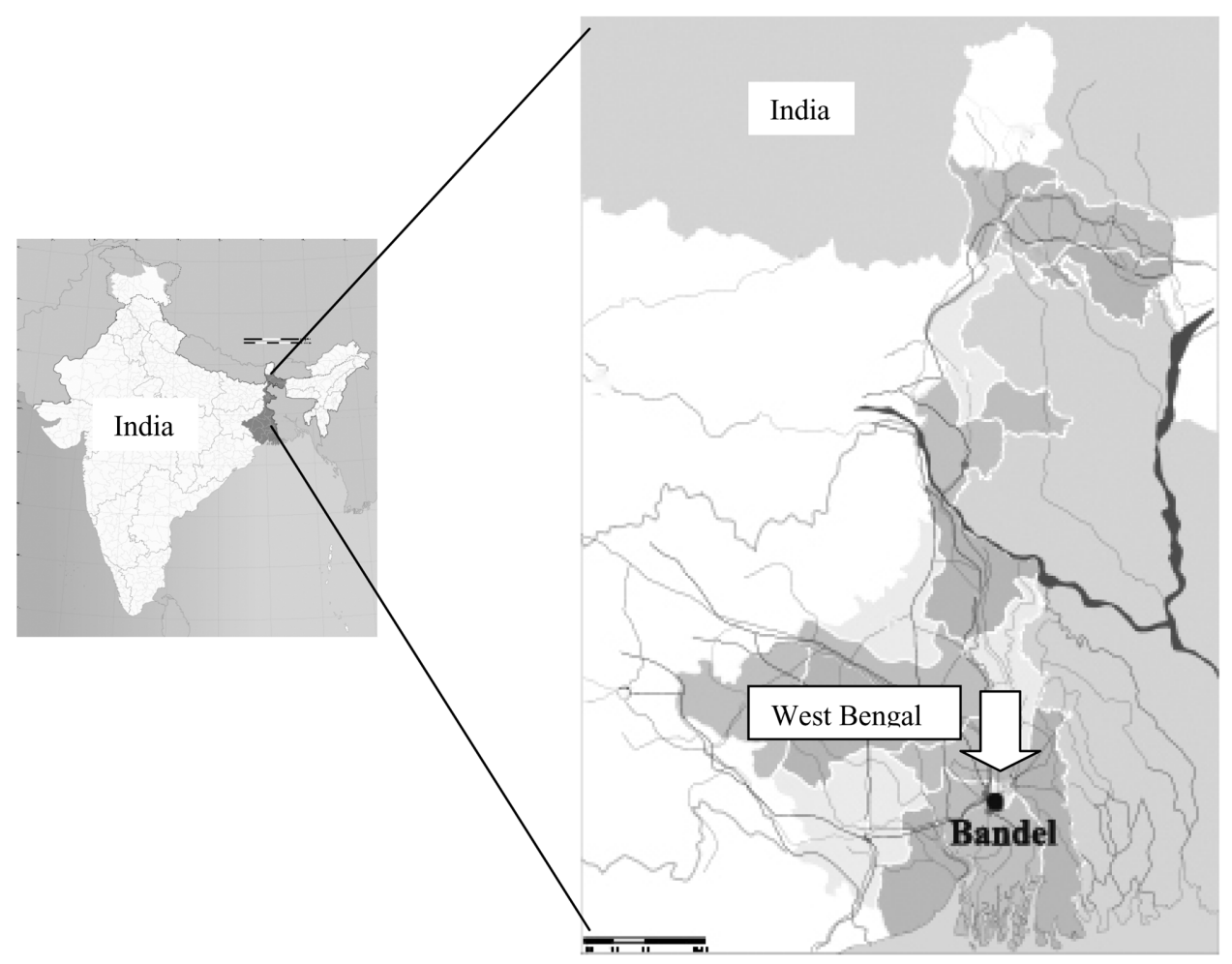

Fig 1. Location of the study area. Bandel, India $\left(22^{\circ} 52^{\prime} 22^{\prime \prime} \mathrm{N} / 88^{\circ} 22^{\prime} 53^{\prime \prime} \mathrm{E}\right)$. 


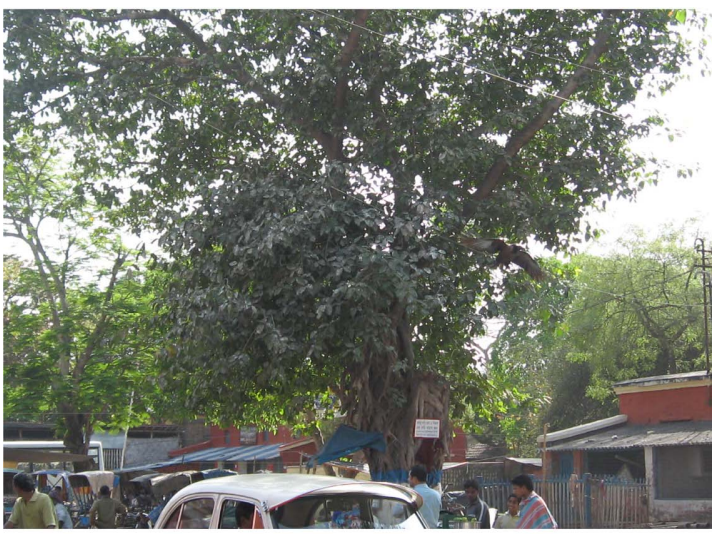

(a) One of the sampling sites: Bandel railway station.

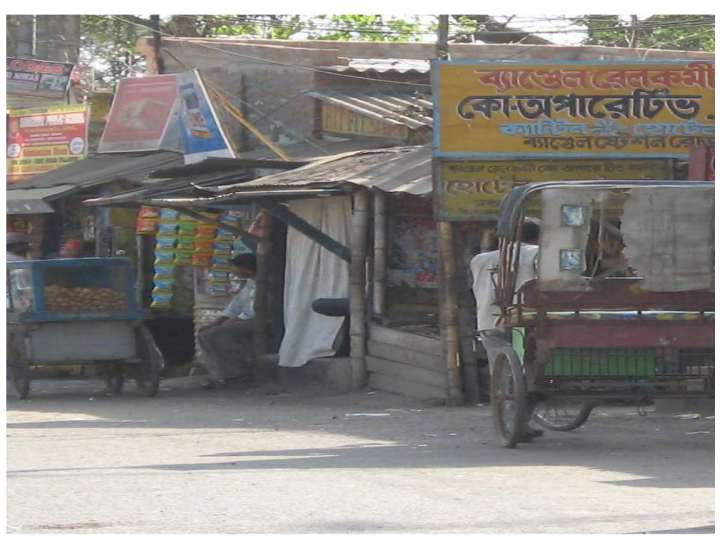

(b) Sampling site 1 - Bandel railway station market.

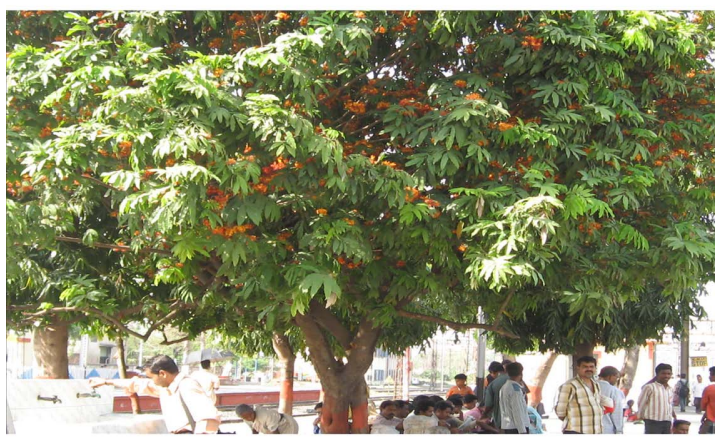

(c) Nesting site of Sparrow

Fig. 2. Sampling sites for counting of house sparrows in Bandel, West Bengal, India; (a) Bandel railway station. (b) Bandel railway station market. and (c) Nesting site of sparrows.

daily intervals on the basis of visual observation using a simple counting method in the morning (5:30-6:30 a.m). This was the time of the day, when they stay continuously in the tree. The number of sparrows in different seasons varied from 250- 277, as presented in Table 1.

From the statistical analysis (chi-square test), it is found that the abundance of house sparrow in different locations is significantly different. Changes in the population do not appear to vary between seasons. At about 4 to $4: 30 \mathrm{pm}$, they came back to the trees to spend the night. It is also noticed that they prefer the dark site of the tree. The noise levels were measured throughout the day from 4:30 am to 10:30 pm once in every thirty minutes.

It is interesting to find that the number of sparrows spotted at the market is always greater than those spotted at the railway station. It proves that because of the food availability, sparrows also came from other locations to the station. Atmospheric profile of illumination level, sound level, and variation of temperature are shown in Table 2.

In both sampling sites, the nests were located in the same tree species Pithecolobium dulce, whereas no sparrows were observed in and around the old structures. To obtain the opinion about the decline of sparrow from local public, a survey was conducted among the age group (20-70) in the local areas. All of them agreed with the situation of a rapid decline of house sparrow, although none of them were sure about the reason for such changes. The survey report is given in Table 3.

\section{Possible causes of decline in sparrow population}

A number of hypotheses have been derived as the possible causes of the decline in House Sparrows in urban-suburban habitats: predation, ecological reason, competition, lack of nest sites, disease, food availability and pollution (Summers-Smith, 1999; Daniels, 2008).

Predation: There are three major candidate predators that could conceivably affect House Sparrow numbers: the Tawny Owl (Strix aluco), the domestic or feral cat (Felix catus), and the Sparrowhawk (Accipiter nisus). The major increase in the number of Sparrow hawks that are seen regularly on the outskirts of towns and 
Table 1. Counting of Sparrow Population in Bandel

\begin{tabular}{cccccc}
\hline \hline Place & Sept-Nov & Dec-Feb & March-May & Mean & Frequency (\%) \\
\hline Bandel Station & 115 & 122 & 112 & 116.3 & 44.05 \\
Market & 150 & 128 & 165 & 147.6 & 55.90 \\
Total & 265 & 250 & 277 & 264 & 99.96 \\
\hline
\end{tabular}

Table 2. Profile of environmental conditions during September 2008 to May 2009

\begin{tabular}{ccccc}
\hline \hline Parameter & Mean & Standard deviation & Max & Min \\
\hline Temperature $\left({ }^{\circ} \mathrm{C}\right)$ & 32.40 & 2.74 & 42.2 & 20.4 \\
Sound level (dBA) & 70.63 & 16.50 & 95 & 35 \\
Illumination level (Lux) & 157.59 & 107.58 & 501 & 31 \\
\hline
\end{tabular}

Table 3. Public Survey report on the cause of decline of sparrow population

\begin{tabular}{ccl}
\hline \hline Age Group & Number & \multicolumn{1}{c}{ Comment } \\
\hline$(60-70)$ years & 13 & There was a time when the tree was full of sparrows. Major decrease in past 5 years \\
$(50-60)$ years & 15 & Drastically declined \\
$<50$ years & 17 & The decline is very prominent \\
\hline
\end{tabular}

villages can be a contributing factor. As predation is only one of the several factors affecting prey populations, any regulatory effect it may have been supported or counteracted by other factors (Newton, 1998).

Competition: Inter-specific or intra-specific competition for food is another factor that can regulate House Sparrow numbers. An overlap in food and other resources provides the potential for competition because some of the resources removed by one species might otherwise have been available for a second species (Newton, 1998). When different species feed together on the same food, individuals of a dominant species can greatly reduce the feeding rates of individuals of subordinate species. The Collared Dove and Wood Pigeon Columba palumbus are both granivorous species. As such, they can be the two most likely competing species against House Sparrows for food (Snow and Perrins, 1998).

Lack of nest sites: A lack of holes suitable for nest sites on modern or renovated buildings has been proposed as a possible cause of the sparrow's declining population in London, UK (Vincent, 2005). There has been an increase in the use of plastic fascia boards and the use of contoured tiles (or roofing sheets) to prevent the entry of birds on modern housing. House Sparrows predominantly nest in holes and gaps in soffit boards and under tiles. Therefore, this tendency may have an impact on the availability of nest sites.

A survey undertaken by the RSPB and BBC Radio 4 'Today' programme in 2001 investigated the use of houses for nesting by four bird species (including the House Sparrow) (Wotton et al., 2002). The survey revealed that houses built before 1919 are important as a source of nesting sites for House Sparrows. Wotton et al. (2002) showed that houses built between 1945 and 1984 are more suitable for House Sparrows, if no recent roof repairs had been undertaken. It was also shown that post 1984 homes are less attractive for nesting sparrows, irrespective of the fact whether repairs have been carried out or not. This work has shown that newer buildings with modern materials, and constructed to conform to current building regulations, seem to be generally less suitable for the sparrow's habitation due to the limited access to the roof space (Wotton et al., 2002).

Disease: House Sparrows have the potential to serve as a reservoir of disease in urban and suburban 
areas (Juricova et al., 1998). The infectious disease salmonella is common during winter and spring in free-living wild House Sparrows (Macdonald, 1978). In cases of fatality, the birds show enlargement and congestion of the liver and spleen with liver, lung, muscle and skin abscesses. The spread of disease may be promoted by the close proximity of birds in gardens for communal feeding with bird table and feeders (Macdonald, 1978).

As disease spreads between individual birds, they will become weak prone to more diseases. If an individual lacks immunity, it becomes vulnerable to diverse types of diseases. Disease is increasingly seen as a response not only to parasite infection but also to the overall condition of the host. This makes it hard to separate the effects of disease between the food shortage and other environmental conditions. Therefore deaths from disease are often unlikely to be additive to other mortality (Newton, 1998).

Food availability: David Lack (1954) argued in 'The natural regulation of animal numbers' that initial populations must be regulated by density-dependent mortality factors such as food shortage, predation, parasitism or disease. However, Lack (1954) believed that food shortage was the chief natural factor limiting the numbers of many birds in particular, reproductive rate. Food shortage can also affect individuals directly, by causing the breeding failure or starvation (Newton, 1998).

Environmental Pollutants: Many toxic chemicals are now added continuously to the natural environment, either as pesticides, industrial effluents, or combustion emissions. Some of these chemicals are now regarded as important sources of bird population declines, influencing their distribution and abundance patterns on both local and widespread scales (Newton, 1998). A research conducted in urban Warsaw, Poland showed that the amount of chlorinated hydrocarbons (insecticides) and polychlorinated biphenyls (PCBs) released in the environment (through their application in agriculture, sanitary treatments, and in industry) can account for the death rates of a certain number of House Sparrow nestlings (Karolewski et al., 1991). Romanowski et al. (1991) found that the levels of zinc and lead concentrations in the sparrow's liver were higher in ill and dead nestlings than in healthy ones, when the concentrations of heavy metals were studied in sparrow nestlings in Poland. Also zinc, cadmium, and lead concentrations were higher in the livers of nestlings with delayed development (reduced body weight) as compared to ones with typical weights (Romanowski et al., 1991).

Summers-Smith (2000) believed that a pollutant such as MTBE from vehicle emissions could cut down invertebrate numbers such as aphids. Therefore, the level of pollution may have an indirect impact on the survival of young sparrow nestlings. Levels of MTBE are currently not collated in the UK. However, there is currently no direct evidence that pollution is contributing to the House Sparrow decline (SummersSmith, 2000).

Multiple environmental causes: Assessing the causes of mortality in a bird population is itself not straightforward. Suppose, a bird weakened by food shortage is about to succumb to disease but just before its death it may fall victim to a predator. In this example, food shortage would be the underlying cause of death, while predation can be considered the immediate cause (Newton, 1998). Therefore, we cannot assume that a population may be limited by only one factor, such as food shortage, predation, or disease. In reality, no single factor is likely to account wholly for changes in a given population level (Newton, 1998).

\section{Conclusion}

This study was conducted to provide insights into the changes in population density of house sparrow in different localities of Bandel. From the data available, it can be concluded that in spite of the high noise pollution in one of the busiest railway stations in West Bengal, a population of sparrows has been established. 
It thus suggests that sound pollution is unlikely to exert significant effects to cause declining of sparrow population. It was also observed that the sparrows take rest on the site of the tree where the illumination level is low (30-45 lux). Considering all these aspects, it is most likely that sparrow population is not decreasing because of a single factor. Based on the public opinion, it can be concluded that the sparrow's population is decreasing without specifications of the cause(s). However, several factors (like predation, ecological reason, competition among the same or similar species, lack of nest sites, disease, food availability and pollution) should interact each other to cause the disease or the decrease of sparrow population.

\section{Acknowledgments}

This work was supported by the National Research Foundation of Korea (NRF) grant funded by the Ministry of Education, Science and Technology (MEST) (No. 2009-0093848).

\section{References}

Daniels, R.J.R., 2008, Can we save the sparrow. Current Science, 95, 1527-1528.

Juricova, Z., Pinowski, J., Literak, I., Hahm, K., and Romanowski, J., 1998, Antibodies to Alphaviruses, Flavivirus, and Bunyavirus Arboviruses in House Sparrows and Tree Sparrows in Warsaw. Avian Diseases,
42, 182-185.

Karolewski, M., Lukowski, A., Pinowski, J., and Trojanowski, J., 1991, The International Symposium of the Working Group on Granivorous Birds. Chlorinated hydrocarbons in eggs and nestlings of Passer montanus and Passer domesticus from urban and suburban Warsaw-Preliminary Report. In Pinowski, J., Kavanagh, B., and Gorski, W. (eds.), Nestling mortality of granivorous birds due to microorganisms and toxic substances. Polish Scientific Warsaw, Poland, 189-196.

Lack, D., 1954, The natural regulation of animal numbers. Clarendon Press, Oxford, UK, $214 \mathrm{p}$.

Macdonald, J., 1978, Cutaneous Salmonellosis in a House Sparrow. Bird Study, 25, p. 59.

Newton, I., 1998, Population Limitation in Birds. Academic Press Limited, USA, 147 p.

Romanowski, J., Pinowski, J., Sawicka-Kapusta, K. and Wlostowski, T, 1991, The effect of heavy metals upon development and mortality of Passer domesticus and Passer montanus nestlings. In Pinowski, J., Kavanagh, B., and Gorski, W. (eds.), Nestling mortality of granivorous birds due to microorganisms and toxic substances. The International Symposium of the Working Group on Granivorous Birds, 197-204.

Snow, D.W. and Perrins, C., 1998, The Birds of the Western Palearctic; Volume 1 nonpasserines. Oxford University Press, UK, $143 \mathrm{p}$.

Summers-Smith, D., 1999, Current status of the House Sparrow in Britain. British Wildlife, UK, 381-386.

Summers-Smith, D., 2000, Decline of House Sparrows in Large Towns. British Birds, UK, $93 \mathrm{p}$.

Vincent, K.E., 2005, Investigating the causes of the decline of the urban house sparrow population in Britain. Ph.D. thesis, De Montfort University, 302 p.

Wotton, S., Field, R., Langston, R., and Gibbons, D., 2002, Homes for Birds: The use of houses for nesting by birds in the UK. British Birds, 95, 586-592. 